\title{
Isolation and Identification of gram positive and negative bacteria from dairy department waste lines at Baraton University
}

\author{
Author: Stella Wanyama \\ Department of Biological Science, Faculty of Science and Technology at University of Eastern \\ African, Baraton.
}

\begin{abstract}
Correspondence Author:
Stella Wanyama

ste2007yama@yahoo.com

Phone: 0724817104

https://orcid.org/0000-0002-

$\underline{3819-1485}$
\end{abstract}

University of Eastern African,

Baraton. registrar@ueab.ac.ke

info@ueab.ac.ke

+254719617586 or +254780

183377

\begin{abstract}
Baraton University dairy farm is an environment that attracts a microbiologist to inquire the composition of bacteria that exist there in. The knowledge of bacteria has in time and again amazed the life scientist community that have invested to acquire more information in this microbiology world. The study engages fundamental tests such as gram stain, endospore stain, and assays for specific microbial activities \& enzymes, susceptibility on disinfectant and antibiotic, utilization of specific substrate and culture characteristics. The two organisms (gram negative and positive) tested positive for sucrose \& lactose fermentation, Indole \& Methly red, catalase \& Oxidase, were both facultative and motile. On contrary, gram positive bacteria had spores and had a gamma haemolysis on Blood Agar, while gram negative bacteria haemolysed beta haemolysis. To draw a conclusion on the identity of the two organisms is that, the gram positive is a Bacillus, while gram negative is Escherichia coli.
\end{abstract}

Keywords: microbial classification; grams stain; endospore stain; susceptibility; substrate

\section{Introduction}

Baraton University dairy farm is a source of delicious and nutritious milk, one of its kinds. The milk is consumed as yoghurt, mala, ice cream and fresh milk by the students, residential faculty members and to the rest of the Baraton Community. As a system the farm intentionally inoculates bacteria for production of yoghurt and mala. While non-intention \& by nature providences some bacteria grow and carry out the metabolic activities.

The dairy department is composed of three major facilities: the processing, milking and cattle feeding $\&$ resting structures. Mainly the cattle feed on hay made of maize stalk from the farm. The drainage from these facilities meets at some point. The three units are sources of enteric bacteria, mycobacterium and other parasites that are associated with cattle breeding (3).

The study primarily is to establish a pure culture of gram positive and negative bacteria and use special staining, assays for specific activities \& microbial enzymes, effects of disinfectants and antibiotic micro-organism, selective and differential media and culture characteristics such as oxygen requirement for organism growth, organism motility $\&$ hemolysis pattern to identify the taxonomical name of the bacteria found at the dairy department waste system. 


\section{Materials \& Method}

The aseptic technique was used in dipping a sterile swab into the specimen from the waste drainage and inoculated into TSB culture media. Three inoculated culture media were established; culture A and $\mathrm{B}$ were incubated at $37^{\circ} \mathrm{C}$ while culture $\mathrm{C}$ was kept at room temperatures to determine the growth of the organism at ambient temperature for 48 hours.

Three plates of TSA culture were obtain to established colonies and a gram stain was done to acquire a gram positive and negative bacteria by heat fixing, application of crystal violet and using iodine solution as mordant, thereafter a decolourization was carried out and finally counter stained with safranin . The cell shape and arrangement were determined through the use of a microscope. Parts of the stained colonies were inoculated by use of quadrant streaking to create pure cultures of gram positive and negative of unknown microorganisms (1).

An acid fast stain was applied to both gram positive and negative bacteria by use of Kinyoun's carbolfuchsin, decolorized with Acid - alcohol solution and counter stained with Leoffler's methylene blue and exposed to steam \& heat control. The applications of Acid fast stain to confirm the presence of mycobacterium spp. identified in the cause of Tuberculosis in both cattle and human $(2,5)$. To ascertain the formation of endospore in bacteria vegetative cells such as Bacillus anthracis, schaeffer Fulton is the method, which involves fixed slides for two cultures, saturated with Malachite Green for 10 minutes by use of steam, rinsed and counter stained with Safranin $(4,6)$.

The two cultures were tested for acid and gas production from carbohydrate fermentation, mixed acid fermentation pathways, presence of acetoine and citrate utilization through the use of lactose broth, Voges-Proskaurer test and Simmons citrate respectively. The production of enzymes: catalase, oxidase, phenylalanine, deaminase, tryptophanase, amylase, and gelatinase were tested. Selective and differential media was used to ascertain whether the unknown organisms are lactose, mannitol, and sucrose \& glucose fermenters.

Special features such as oxygen requirement for organisms' growth, their motility and hemolysis pattern were tested through growth analysis on thioglycollate broth, motility media and Blood Agar Plates.

The susceptibility to disinfectant of the two cultures was determined by exposure to $10 \%$ omo, $10 \%$ jik, $10 \%$ dettol and $70 \%$ ethyl alcohol. The Kirby bauer disk method was also carried to determine the susceptibility of ampicillin, lincomycin, penincilin, minocycline, erythromycin, chloramphenical and co-trimoxazole.

\section{Results}

The conjunction point of the drainage constituted of green and turbid sewage that produced a strong odour. Apart from the cattle waste, a combat liquid soap was evident in the sewage. It was an attractive site to investigate the bacteria growth. Inoculation of the specimen in TSB, produced a saturated TBS with bacteria growth. Three TSA plate show cased different colonies in size, colour and shape. Gram positive presenting large single blue rods, while gram negative produced short single rods. The selections were picked out of the numerous colonies on TSA plates.

Table 1 show casing tests results and characteristics of gram positive and negative bacteria. 


\begin{tabular}{|l|l|l|}
\hline $\begin{array}{l}\text { Tests and Morphological } \\
\text { \&Culture characteristics }\end{array}$ & Gram Positive Bacteria & Gram Negative Bacteria \\
\hline Acid Fast & Negative & Negative \\
\hline Endospore & positive & Negative \\
\hline Lactose broth & Positive & Positive \\
\hline Maconkey agar & Positive & Positive \\
\hline Triple -sugar Iron & $\begin{array}{l}\text { Acid and gas production } \\
\text { (Lactose and sucrose } \\
\text { fermentation) }\end{array}$ & $\begin{array}{l}\text { Acid and gas production } \\
\text { (Lactose and sucrose } \\
\text { fermentation) }\end{array}$ \\
\hline Mannitol salt agar & Negative & Negative \\
\hline Gelatinase & Negative & Negative \\
\hline Amylase & Negative & Negative \\
\hline urease & Negative & Negative \\
\hline Catalase & Positive & Positive \\
\hline Oxidase & Positive & Positive \\
\hline Phenylalanine Deaminase & Negative & Negative \\
\hline Indole (Tryptophanase) & Positive & Positive \\
\hline Methly red & Positive & Positive \\
\hline Voges proskauer Test & Negative & Negative \\
\hline Citrate Utilization & Negative & Negative \\
\hline Cell shape and arrangement & Large single rods & Short single rods \\
\hline Oxygen requirement & Facultative & Facultative \\
\hline Hemolysis pattern & Gamma & Beta \\
\hline Motility & Show movement & Show movement \\
\hline & & \\
\hline
\end{tabular}

Special staining for Acid fast generated bright shinny rods from gram positive culture while blue rods from gram negative culture. An Endospore stain, microscopy observation demonstrated free spores and endospores in vegetative cell stained blue green for gram positive and reddish pink cell for gram negative.

Both gram positive and negative bacteria fermented lactose \& produced gas and carried out mixed acid fermentation pathways but did not ferment mannitol, do not utilise citrate, nor produce acetoine. Among the enzymes tested, the two organisms do not produce phenylalanine deaminase, amylase and urease but generate tryptophanase.

The susceptibility test demonstrated gram positive resistance to all detergents, lincomycin, penincilin and minocycline. Inhibition zones were not observed around disks of the detergents and antibiotics. Inhibition zones were illustrated by some antibiotics A $(1 \mathrm{~cm}), \mathrm{Mi}(1.8 \mathrm{~cm}), \mathrm{E}(1.6 \mathrm{~cm}), \mathrm{CO}(2.5 \mathrm{~cm})$, and $\mathrm{C}(2 \mathrm{~cm})$. The gram negative exhibited no inhibition zones with ethyl alcohol, L,P, and $\mathrm{M}$. While demonstrated inhibitions zones with omo $(1.7 \mathrm{~cm})$, jik $(1 \mathrm{~cm})$, dettol $(1.1 \mathrm{~cm}), \mathrm{A}(1 \mathrm{~cm}), \operatorname{Mi}(2.5)$, $\mathrm{E}(1.6 \mathrm{~cm}), \mathrm{CO}(1 \mathrm{~cm})$, and $\mathrm{C}(2.6 \mathrm{~cm})$.

The organisms are motile, facultative and illustrated gamma hemolysis for gram positive and beta hemolysis for gram negative.

\section{Discussion and Conclusion}


The organisms' habitat detects presence of gram positive and negative enterobacteriaceae group of bacteria, whereby most of these bacteria carry out mixed acid fermentation and grow at low PH detected in Methly red tests . VP test is used widely to classify enterobacteriaceae strains, those bacteria that produce acetoin are VP test positive. In this case acetoin increase the PH by reducing the acid in the environment or medium $(8,21)$. Some cultures, with prolonged time of growth (to seven days) have tested VP positive. As a result, acidity is reduced in the media (7). Barry and Feeney declares that acetoin can be detected a little faster if creatine was added to MR VP broth followed by Barritt reagents (9).

Endospore formation on gram positive cells has an ability to create resistance to some antibiotics and detergents as described in the results, there were no inhibition zones. The spores and endospore were quite evident in both Endospore and Acid Fast Staining. Acid Fast Staining of gram positive bacteria demonstrated refractile bodies of endospore and free spores (6).

Ampicillin is used as plasmid maintaining agent during Escherichia coli MG 1655 cultivation (7). Ampicillin does not necessitate limitation of growth but plasmid transfer as demonstrated by lack of inhibition zones in gram positive and negative. Lactic acid bacteria can be used as antibiotic against E. coli and Klebsialla spp. Escherichia coli is the most resistant bacteria and therefore lactic acid bacteria antibiotic activities is a solution to antibiotic resistant that is transmitted to Human population (10). The susceptibility to antibiotic greatly depends on the environment, therefore to determine the resistance of bacteria on host, requires an environment resembling the host (13). Pre exposure to some antibiotics or detergents can create resistance of bacteria towards other antibiotics or detergents (15).

Escherichia coli are used as a control for detection of tryptophanase. According to Newton and Shell tryptophanase in Escherichia coli catalyses this reaction L-Tryptophan + H20 - indole + pyruvate + NH3 $(10,14)$.

In normal circumstances and anatomical structure of Escherichia coli do not support acetoin production and citrate utilization. Therefore, VP and citrate tests are supposable negative. The transfers of plasmid in Isolates of different species and environment have proved utilization of citrate. Generation of acetoin by Escherichia coli strains in vegetables and fruits due to acquisition of buidAB gene alter the normal functionality of Escherichia coli. These two phenomena leads to misdiagnosis of $E$. $\operatorname{coli}(7,17)$.

Presence of catalase reinforces the facultative ability demonstrated the thioglycollate broth as most bacteria from the family of Enterobacteriaceae that are either aerobic or facultative produce catalase enzymes (11). Escherichia Coli exhibit a number of cytochrome oxidase such as cytochrome c oxidase, cytochrome bd oxidase and cytochrome bo oxidase that aid it to survive in different habitat. Cytochrome bd oxidase has proved to be pathogenetic enhancer when exposed to NO and enhances respiration in hydrogen sulphide environment $(12,16)$. Tryptophan utilization by tryptophanase (18) generates sulphide in Escherichia coli that triggers cytochrome bd oxidase mechanism (16).

In the experiment the two bacteria culture indicated movement, their growth extended away from the inoculation line. E coli have capabilities of swimming and swarming through the environment by use of flagella and as a colony in search of energy and detecting of some substances $(19,20)$.

The results presented two types of hemolysis; Gamma hemolysis for gram positive bacteria which indicates the absences red blood cells lysing due to lack of toxin production. Beta hemolysis in gram negative bacteria is due to toxin production. E. coli strains such as Escherichia coli O157, 
enteropathogenic Escherichia coli and Shiga Toxin-Producing E. coli are sources of toxin that lyses red blood cells $(22,23,24)$.

Author's Contribution: Stella carried out the experiments and authored this article.

Conflict of Interest: There is no conflict of interest

Funds: This research received no external funding.

\section{Reference}

1. Scott F., Jason R. S., H. M. Lappin-Scott, and Jonathan P. Simultaneous Fluorescent Gram Staining and Activity Assessment. Applied and Environmental Microbiology. 2002; 68(10): 4772-4779. Available from:doi:10.1128/AEM.68.10.4772-4779.2002

2. $\quad$ Eric M. F., William A., Lian F. T., Elizabeth A. J. C., Samuel K. and Claire N. W. An integrated study of human and animal infectious disease in the Lake Victoria crescent small-holder crop-livestock production system, Kenya. BMC Infectious Diseases. 2017;(17)457 DOI 10.1186/s12879-017-2559-6

3. I.M. AL-Saqur, A.N. AL-Thwani, I.M. AL-Attar, M.S. AL-Mashhadani . Evaluation the virulence of Mycobacterium bovis isolated from milk samples through histopathological study in laboratory animals. International Journal of Mycobacteriology. 2016; (5) S90 S91 http://dx.doi.org/10.1016/j.ijmyco.2016.11.026

4. A. Oktari, Y. Supriatin, M. Kamal and H. Syafrullah. The Bacterial Endospore Stain on Schaeffer Fulton using Variation of Methylene Blue Solution. Journal. Physic.: Conf.Ser. 812 012066. IOP. 2017 doi:10.1088/1742-6596/812/1/012066

5. Daniel P. N., Adrian M., Clovice K. and Francisco O. Prevalence of tuberculous lesion in cattle slaughtered in Mubende district, Uganda. BMC Veterinary Research. 2017; 13(73) doi 10.1186/s12917-017-0991-x

6. Marise A. Hussey and Anne Zayaitz. Endospore Stain Protocol. Washington, DC: ASM; 2007.

7. Bram Vivijs, Pieter Moons, Abram Aertsen, and Chris W. Michiels. Acetoin Synthesis Acquisition Favors Escherichia coli Growth at Low pH. Applied and Environmental Microbiology. 2014; 80 (19): 6054-6061.

8. Klaus Bryn, Jan C. Ulstrup, and Fredrik C. Størmer. Effect of Acetate upon the Formation of Acetoin in Klebsiella and Enterobacter and its Possible Practical Application in a Rapid Voges-Proskauer Test. Appld Microbiology.1973;25(3):511-512

9. A. L. Barry and K. L. Feeney. Two Quick Methods for Voges-Proskauer Test. Applied Microbiology.1967;15(5):1138-1141

10. Adeniyi BA, Adetoye A, Ayeni FA. Antibacterial activities of lactic acid bacteria isolated from cow faeces against potential enteric pathogens. Afri Health Sci. 2015;15 (3):888-95. doi: http://dx.doi.org/10.4314/ahs.v15i3.

11. Welton I. Taylor and David Achanzar. Catalase Test as an Aid to the Identification of Enterobacteriaceae. Applied Microbiology.1972; 24 (1): 58-61. 
12. Alessandro G., Vitaliy B. B., Daniela M., Paolo S., Elena F., Cytochrome bd oxidase and nitric oxide: From reaction mechanisms to bacterial physiology. FEBS Letters. 2012; 586: 622-629

13. Zachary D., Silpak B., Raghavendra G., and David G. R. Antimicrobial Susceptibility of Enteric Gram Negative Facultative Anaerobe Bacilli in Aerobic versus Anaerobic Condition. Plos One. 2016; 11(5): 1-12. doi:10.1371/journal.pone.0155599

14. W. Austin Newton and Esmond E. Snell Catalytic Properties of Tryptophanase, A Multifunctional Pyridoxal Phosphate Enzyme. Biochemistry.1964; 51: 382-389.

15. Gang Liu, Laidi Ding, Bo Han, Sofie Piepers, S. Ali Naqvi, HermanW. Barkema, et al. Characteristics of Escherichia coli Isolated from Bovine MastitisExposed to Subminimum Inhibitory Concentrations of Cefalotin or Ceftazidime. Biomed Research International. 2018; 2018 (4301628): 1-10. doi.org/10.1155/2018/4301628

16. Sergey Korshunov, Karin R. C. Imlay, and James A. Imlay. The cytochrome $b d$ oxidase of Escherichia coli prevents respiratory inhibition by endogenous and exogenous hydrogen sulphide. Mol Microbiol. 2016; 101(1): 62-77. doi:10.1111/mmi.13372

17. Naotaka Ishiguro and Gihei Sato. The distribution of plasmids determining citrate utilization in citrate-positive variants of Escherichia coli from humans, domestic animals, feral birds and environments J. Hyg., 1979; 83: 331-344

18. Gunnar D. Fay and Arthur L. Barry. Methods for Detecting Indole Production by GramNegative Nonsporeforming Anaerobes. Applied Microbiology.1974;27 (3):562-565

19. Jayamary Divya Ravichandar, Adam G. Bower, A. Agung Julius4 \& Cynthia H. Collins Transcriptional control of motility enables directional movement of Escherichia coli in a signal gradient. Scientific Reports. 2017; 7: 8959 doi:10.1038/s41598-017-08870-6

20. José-María Gómez-Gómez, Candela Manfredi, Juan-Carlos Alonso and Jesús Blázquez. A novel role for RecA under non-stress: promotion of swarming motility in Escherichia coli K-12. BMC Biology. 2007; 5:14 doi:10.1186/1741-7007-5-14

21. S. M. Hussain Qadri, C. W. Nicholas, S. G. M. Qadri, and Anita V. Rapid Test for AcetylMethyl-Carbinol Formation by Enterobacteriaceae. Journal of Clinical Microbiology. 1978; 8 (4): 463-464.

22. Rebecca Buxton. Blood Agar Plates and Hemolysis Protocols. American Society for Microbiology. 2005.

23. Michael A. Hornitzky, Kim Mercieca, Karl A. Bettelheim, and Steven P. Djordjevic. Bovine Feces from Animals with Gastrointestinal Infections Are a Source of Serologically Diverse Atypical Enteropathogenic Escherichia coli and Shiga Toxin-Producing E. coli Strains That Commonly Possess Intimin. Applied and Enviromental Microbiology. 2005; 71 (7): 3405-3412. doi:10.1128/AEM.71.7.3405-3412.2005

24. Shin Sata, Tomohiko Fujisawa, Ro Osawa, Atsushi Iguchi, Shiro Yamai, and Toshio Shimada. An Improved Enrichment Broth for Isolation of Escherichia coli O157, with Specific Reference to Starved Cells, from Radish Sprouts. Applied and Environmental Microbiology.2003; 69 (3): 1858-1860. doi: 10.1128/AEM.69.3.1858-1860.2003 